\title{
Workload, diagnostic work-up and treatment of urinary tract infections in adults during out-of-hours primary care: a retrospective cohort study
}

\author{
Michelle Spek ${ }^{1}$, Jochen W. L. Cals ${ }^{1}$, Guy J. Oudhuis ${ }^{2}$, Paul H. M. Savelkoul ${ }^{2}$ and Eefje G. P. M. de Bont ${ }^{1 *}$ (D)
}

\begin{abstract}
Background: Urinary tract infections (UTIs) are one of the most common infections in primary care. Previous research showed that GPs find it challenging to diagnose UTIs and frequently divert from guidelines leading to unwarranted antibiotic prescriptions and inefficient use of diagnostics such as urinary cultures. We hypothesise that management of UTIs during out-of-hours care may be extra challenging due to a higher workload and logistical issues regarding diagnostic work-up and obtaining results. We therefore aimed to study the workload, diagnostic work-up and treatment of UTIs during out-of-hours primary care.

Methods: We performed a retrospective observational cohort study in which we analysed a full year (2018) of electronic patient records of two large Dutch GP out-of-hours centres. All adult patients with UTI symptoms were included in this study. Descriptive statistics and multivariate regression were used to analyse diagnostics and subsequent management.

Results: A total of 5657 patients were included (78.9\% female, mean age of 54 years), with an average of eight patients per day that contact a GP out-of-hours centre because of UTI symptoms. Urinary dipsticks were used in $87.5 \%$ of all patients visiting the out-of-hours centres with UTI symptoms. Strikingly, urinary cultures were only requested in $10.3 \%$ of patients in which urinary culture was indicated. Seventy-four percent of the patients received antibiotics. Seventy-nine percent of the patients with a negative nitrite test still received antibiotics. Remarkably, patients at risk of complications because of a UTI, such as men, received fewer antibiotic prescriptions.

Conclusions: In total, 74\% of the patients received antibiotics. 8 out of 10 patients still received an antibiotic prescription in case of a negative nitrite test, and 9 out of 10 patients with an indication did not receive a urine culture. In conclusion, we found that correctly diagnosing UTIs and prescribing antibiotics for UTIs is a challenge that needs major improvement, especially during out-of-hours GP care.
\end{abstract}

Keywords: Urinary tract infections, Out-of-hours primary care, General practice, Cultures, Antibiotics

\footnotetext{
* Correspondence: eefje.debont@maastrichtuniversity.nl

'Department of Family Medicine, CAPHRI Care and Public Health Research Institute, Maastricht University Medical Centre, P.O. Box 616, Maastricht, MD 6200, The Netherlands

Full list of author information is available at the end of the article
}

(c) The Author(s). 2020 Open Access This article is licensed under a Creative Commons Attribution 4.0 International License, which permits use, sharing, adaptation, distribution and reproduction in any medium or format, as long as you give appropriate credit to the original author(s) and the source, provide a link to the Creative Commons licence, and indicate if changes were made. The images or other third party material in this article are included in the article's Creative Commons licence, unless indicated otherwise in a credit line to the material. If material is not included in the article's Creative Commons licence and your intended use is not permitted by statutory regulation or exceeds the permitted use, you will need to obtain permission directly from the copyright holder. To view a copy of this licence, visit http://creativecommons.org/licenses/by/4.0/. The Creative Commons Public Domain Dedication waiver (http://creativecommons.org/publicdomain/zero/1.0/) applies to the data made available in this article, unless otherwise stated in a credit line to the data. 


\section{Background}

Urinary tract infections (UTIs) are one of the most common infections in primary care and are characterized by dysuria, frequency, and urgency for micturition [1-3]. However, these symptoms are not specific for UTIs. UTIs vary in severity from uncomplicated cystitis to prostatitis or even pyelonephritis [4]. Annually, around 58 out of 1000 inhabitants of the Netherlands are diagnosed with a cystitis by their general practitioner (GP) [5]. Incidence rates are higher in women (70 out of $1000)$, compared to men (10 out of 1000). Based on this, UTIs are the most common complaint in women in primary care.

Incorrect diagnosis has a considerable impact on antibiotic resistance in case of overdiagnosis, or patient's health in case of underdiagnosis. There is increasing evidence in literature that recognizes the worldwide problem of emerging antibiotic resistance [6, 7]. In comparison to other European countries, antibiotic prescription rates in the Netherlands are relatively low [8], and consumption is more or less stable over time [9]. However, accurate UTI diagnostics and subsequent antibiotic management is still challenging.

The guideline of the Dutch College of General Practitioners on UTIs describes the diagnostic criteria and corresponding management for Dutch patients with a putative UTI $[10,11]$. Most UTI management is based on patient symptoms and subsequent prescription of empirical antibiotics [6]. Physicians can also perform additional diagnostic tests such as urine dipstick, a urine dip slide or a urine culture $[11,12]$. The most commonly used diagnostic tool, a urine dipstick, provides fast results and is used as point-of-care test. However, diagnostic accuracy is not adequate enough with a positive predictive value of $84 \%$ for the nitrite test and a positive predictive value of $91 \%$, and negative predictive value of $76 \%$ for combination tests also including leukocytes and erythrocytes [13-15]. Although a number of uropathogens can give a negative result of the nitrite test, suggesting erroneously that the patient does not have an UTI, this is currently the most clear point-of-care cutoff test available. The reference standard, urine culture with antimicrobial susceptibility testing, takes two to 3 days and requires a microbiological laboratory [16]. We do however know there is discussion about this reference standard as well since cultures were negative in 20 to $30 \%$ of women with UTI symptoms, while a quantitative Polymerase Chain Reaction (qPCR) showed positive result for a uropathogen [17].

Suboptimal diagnostic procedures can lead to both over- and undertreatment of UTIs. Underdiagnoses of UTIs can lead to serious and potentially life-threatening complications like pyelonephritis or even urosepsis [4]. Furthermore, UTIs can lead to delirium, which is associated with acute care problems in elderly patients [18]. Overdiagnosis happens through empirical antibiotic treatment based on symptoms only or incorrect interpretation or classification of current diagnostic POC (Point-Of-Care) test results. Previous research has shown that $42 \%$ of antibiotic prescription for urinary tract complaints are not in line with guidelines [19]. This can partially be explained by unnecessary antibiotic prescriptions, but also by use of other antibiotics than recommended. This in turn contributes to the increase of antibiotic resistance, reduced treatment options and increasing health care costs $[6,7]$.

Because GPs and patients do not know each other during out-of-hours GP care and GPs do not have access to information on previous UTI episodes and urine cultures, we hypothesize that antibiotic prescription rates are even higher during out-of-hours care. One can assume that with acute onset of symptoms, and daytime GP practices only open during at best $30 \%$ of the $168 \mathrm{~h}$ in a week, a large proportion of UTI management happens at the out-of-hours care [20]. Earlier studies on UTI diagnostics have only focused on appropriateness of current diagnostic tests during daytime practice $[4,8$, 20]. None of these studies analysed the diagnostic process of UTIs during out-of-hours care.

The specific objective of this study was therefore to examine the workload, diagnostic work-up and treatment of UTIs in healthy adults during out-of-hours primary care.

\section{Methods}

We performed a retrospective observational cohort study. Data of electronic patient reports of two GP outof-hours centres (located in Maastricht and Heerlen) in the province of Limburg, the Netherlands, during a full year (2018) were collected anonymously.

GP out-of-hours centres in the Netherlands are organised in large-scale cooperatives. These cooperatives cover primary care by rotating shifts of GPs during evenings, nights, and weekends. Telephone triage is done by triage nurses based on the Dutch triage standard (NTS), after which they decide if a patient has to visit the GP out-of-hours centres or not. The Dutch guidelines describe that patients with signs of tissue invasion or patients belonging to a risk group have to visit the out-of-hours GP centre. General practitioners with experience varying form 3 months to 30 years take care of patients visiting the GP outof-hours centres. Seven GP out-of-hours centres in Limburg are responsible for urgent medical care during non-daytime hours [5]. The two above-mentioned out-of-hours centres are responsible for a population of 444,872 patients from both rural and urban areas and with different socio-economic status [21, 22]. The 
out-of-hours centre in Maastricht is responsible for a population of 179,426 patients and the out-of-hours centre in Heerlen is responsible for a population of 265,446 patients.

We included adult patients who visited one of the participating GP out-of-hours centres with UTI symptoms, defined as:

- ICPC codes: U01 (painful micturition), U02 (frequency), U05 (other micturition problems), U06 (hematuria), U07 (other urinary tract complaints), U70 (pyelonephritis), U71 (cystitis), Y73 (prostatitis);

- Patients with other ICPC codes with triage code 'urinary tract problems' or patients with terms 'urine' or 'urinary tract infection' in their medical report.

Patients with ICPC codes U70 (pyelonephritis), U71 (cystitis) or Y73 (prostatitis) were selected directly, while patients with other ICPC codes were selected if they had symptoms fitting with UTIs such as dysuria, frequency, or urgency for micturition. We therefore screened all patients with ICPC codes other than U70, U71 or Y73 manually and included patients only when the GP considered a UTI.

We excluded patients below the age of 18 years, patients with an indwelling bladder catheter, and patients with bladder malignancy. We defined the following groups as high risk UTI patients, according to the Dutch general practice guideline; men, pregnant women, patients using antibiotic prophylaxis for recurrent UTIs and patients with diabetes mellitus. The decision whether a urinary culture was appropriate and indicated was based on the Dutch general practice guideline. This guideline described that urinary cultures are indicated for high risk UTI patients.

The registered patient data consisted of information from telephone triage, given advice, consultation report, (working) diagnosis, ICPC code, treatment, and prescribed medication.

Primary outcomes were:

1. Number of contacts for UTI symptoms;

2. Number of diagnostic tests performed for UTI symptoms;

3. Antibiotic prescribing rate for UTI symptoms.

Secondary outcomes were:

1. Relationship between age and risk factors, and receiving an antibiotic prescription;

2. Urinary dipstick outcome related to antibiotic prescription.

Data analyses were performed using SPSS 25.0 (2018) and based on frequencies, descriptive statistics and binary logistic regression for antibiotic prescriptions (yes/ no) as an independent outcome.
Relationships between covariates (age, risk factor for complications, outcome of urinary dipstick) and antibiotic prescription rates were analysed using multivariate logistic regression analyses. To determine which factors influence antibiotic prescription, we analysed all patients in our database except for the patients who were referred to the emergency department and the patients who had already received an antibiotic prescription from their own GP.

\section{Results \\ Workload}

In total, 5657 patients contacted the out-of-hours GP centre because of UTI symptoms during the study period. This corresponds with an average of eight patients per day. Most patients were women (78.9\%) with a mean age of 54 years (range 18-104 years).

Figure 1 shows an overview of the diagnostic work-up and management of these patients. As shown in this figure, $59.7 \%$ of the patients visited the out-of-hours centre for a consultation or at least a dipstick, compared to $40.3 \%$ of the patients that only had a telephone contact. Patients visiting the out-of-hours centre were more often patients with one or risk factors (37.5\%) compared to patients that had telephone contact (14.7\%). Furthermore, patients with signs of tissue invasion during telephone triage visited the out-of-hours centre more often (18.1\% versus $2.7 \%$ ). No more than $3.5 \%$ of the patients visiting the out-of-hours centre were referred to the emergency department after consultation.

\section{Diagnostic work-up}

Two diagnostic tests for UTIs were used at the out-ofhours GP centres: the urinary dipstick and urinary culture. The dipstick was used in $87.5 \%$ of all patients that visited the out-of-hours GP centre because of UTI symptoms. However, despite this test, antibiotic prescription rates are the same for patients that visited the out-of-hours GP centre and patient that had telephone contact consultation only.

Table 1 shows the amount of ordered cultures for the group with an indication for a culture and the group without an indication.

In total, 229 cultures were ordered. $96.3 \%$ of the patients without an indication did not receive a urinary culture. However, almost half of the cultures that were ordered were for patients without an indication for a urinary culture. Furthermore, $89.7 \%$ of all patients who had an indication for a urinary culture did not receive a urine culture at the out-of-hours GP centre.

\section{Treatment}

Of the patients that contacted or visited the out-ofhours GP centre $74.2 \%$ received antibiotics. Of these 


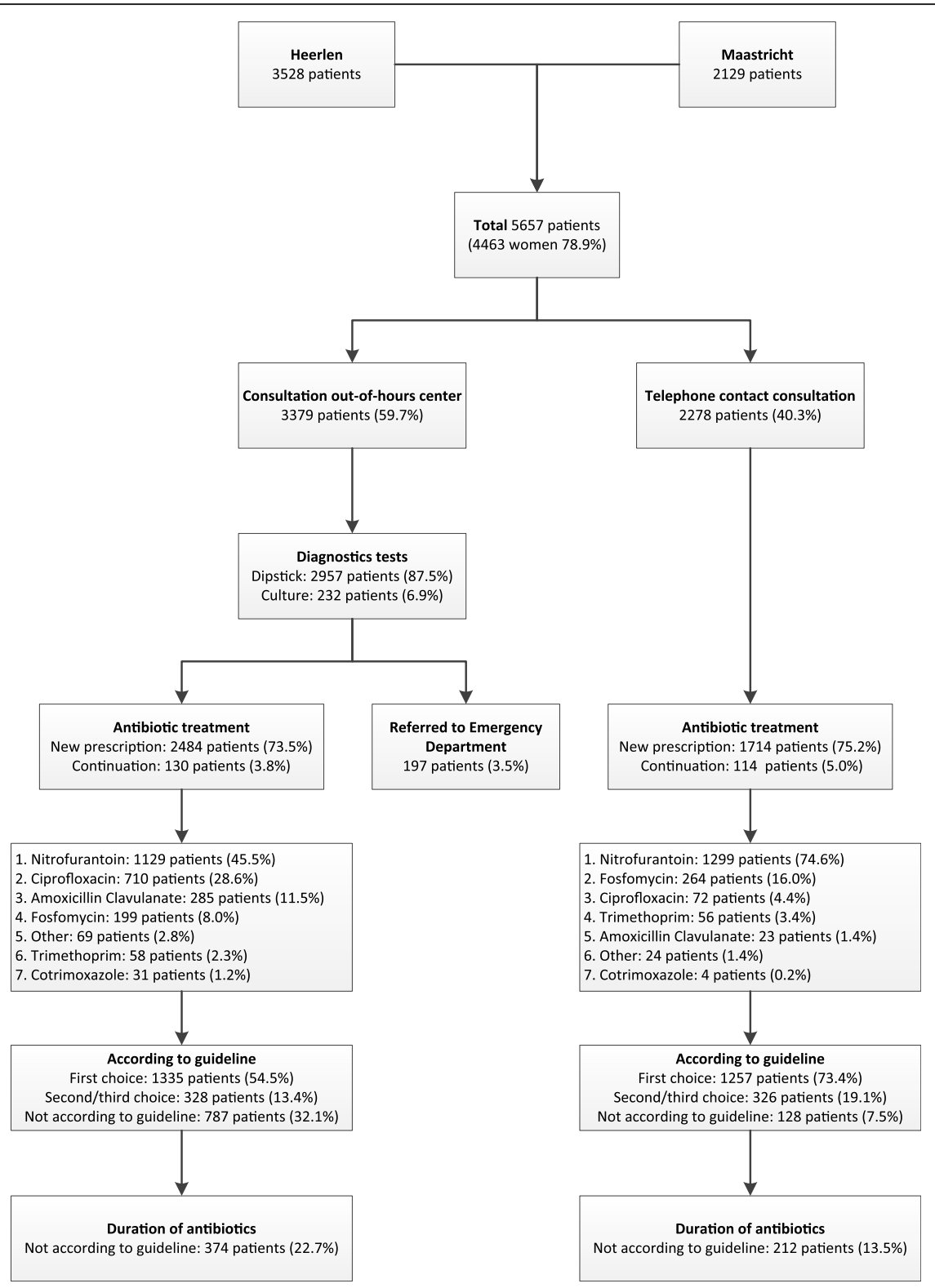

Fig. 1 Flowchart showing the workload, diagnostics and management within patients that contacted GP out-of-hours care because of urinary tract infection symptoms

Table 1 Urine cultures in patients at the out-of-hours GP centres

\begin{tabular}{lll}
\hline & Indication (\%) & No indication (\%) \\
\hline Total number of patients & $1552(29.8)$ & $3663(70.2)$ \\
Culture not ordered & $1392(89.7)$ & $3526(96.3)$ \\
Culture ordered & $127(8.2)$ & $102(2.8)$ \\
Referred to own GP & $22(1.4)$ & $22(0.6)$ \\
Ordered by own GP & $13(0.7)$ & $11(0.4)$ \\
\hline
\end{tabular}

Patients referred to the emergency department or patients who already received antibiotics from their own GP were excluded from this analysis antibiotic prescriptions $40.8 \%$ were given after telephonic contact without a physical consultation at the out-of-hours centre. A small proportion of the patients (3.8\% of the consultation group and $5.0 \%$ of the telephonic consultation group) already had antibiotics prescribed by their own GP leading to no new antibiotic prescription in these patients.

An important finding was non-accordance to the guideline resulting in prescription of antibiotics that are not in line with the guidelines in more than 1 out of 5 patients. Furthermore, antibiotic prescription was more 
in line with the guidelines after telephone contact consultation compared to a consultation at the out-of-hours GP centre. Besides, the duration of antibiotics is not in line with the guidelines in more than $20 \%$ of the patients that visited the out-of-hours GP centre. Some of these patients received a too long prescription, while the prescription was too short in other patients.

Age did not significantly influence antibiotic prescription rates (median age 52 years non-antibiotic group versus 54 years in antibiotic group).

Table 2 presents the results of the multivariate logistic regression analyses studying which risk factors influence antibiotic prescription.

As shown in the table above, a negative correlation was found between the risk factors: gender (male) and pregnancy, and antibiotic prescription. Antibiotic prescription rates appeared to be unaffected by diabetes mellitus and the use of antibiotic prophylaxis for recurrent UTIs.

Almost all patients (98.1\%) received antibiotics in case of a positive dipstick for nitrite. However, in case of a negative dipstick for nitrite, $78.8 \%$ the patients received antibiotics as well. A positive dipstick for nitrite was a predictor for antibiotic prescription with an adjusted OR (corrected for age, gender, risk factors, and results of leukocytes and erythrocytes in the dipstick) of 14.2 (95\% CI.: 8.1-24.8).

In case of a negative dipstick for leukocytes, $64.7 \%$ of the patients received antibiotics. Leukocytes in a dipstick test was a predictor for antibiotic prescription with an adjusted OR (corrected for age, gender, risk factors, and results of nitrite and erythrocytes in the dipstick) of 2.0 (95\% CI.: 1.8-2.2).

In case of a negative dipstick for erythrocytes, $74.7 \%$ of the patients received antibiotics. Erythrocytes in a dipstick test was a predictor for antibiotic prescription with an adjusted OR (corrected for age, gender, risk factors, and results of leukocytes and nitrite in the dipstick) of 1.2 (1.1-1.3).

\section{Discussion}

An average of eight patients per day contacted the GP out-of-hours centre because of UTI symptoms. In total,
$74 \%$ of the patients contacting the GP out-of-hours centre because of UTI symptoms received antibiotics. Urinary dipstick was used in almost all patients (87.5\%) that visited the out-of-hours GP centre with UTI symptoms, but 8 out of 10 patients still received an antibiotic prescription in case of a negative nitrite test. Furthermore, 9 out of 10 patients with an indication did not receive a urine culture, while $44.5 \%$ of all cultures ordered at the out-of-hours GP centre were for patients without an indication for a urinary culture.

In agreement with our study, studies from other countries and studies performed in regular GP practices have shown that chosen diagnostics, in most cases, do not correspond to guidelines $[8,22]$. A recent Dutch study during office hours has shown that recommendations for ordering urinary cultures in risk groups, such as pregnant women, and not using urinary cultures in nonrisk groups are often not applied in daily practice [4]. This is striking while these criteria are clearly described in the guidelines and GPs have access to full medical reports of their own patients.

As hypothesised, our study showed an even lower number of correctly ordered cultures of one out of ten patients $[4,8,23]$. This is far below the one out of three that was found in an earlier study during office hours [4]. A possible explanation for this difference could be that GPs could feel less responsible for urine cultures of patients if they are not confronted with eventual problems during follow-up, because patients will visit their own GP for this. Another reason for GPs not performing urine cultures at the out-of-hours care could be the inability to safely follow-up the result, while they are responsible for this when they request the culture. A third explanation for this was shown in our database, where some GPs said that patients should visit their own GP for a culture while this is not possible during out-of-our care. This implicates that GPs are either unaware of the fact that cultures are possible during out-of-hours care or experience (time) barriers to perform a culture during out-of-hours care. This while patients consulting out-ofhours care have a higher risk of complications and

Table 2 Influence of risk factors on antibiotic prescription

\begin{tabular}{lllll}
\hline & $\mathbf{n ~ ( \% )}$ & Antibiotic prescription (\%) & Unadjusted OR (95\% Cl) & Adjusted OR(95\% Cl) \\
\hline Total & $5215(100)$ & $4195(80.4)$ & - & - \\
Low-risk for complications & $3819(73.2)$ & $3299(86.4)$ & - & - \\
High-risk ( $\geq 1$ risk factor) & $1396(26.8)$ & $896(64.2)$ & $0.3(0.2-0.3)^{*}$ & $0.4(0.3-0.5)^{*}$ \\
Male gender & $1030(19.8)$ & $630(61.2)$ & $0.3(0.2-0.3)^{*}$ & $0.4(0.3-0.5)^{*}$ \\
DM & $282(5.4)$ & $229(81.2)$ & $1.1(0.8-1.4)$ & $1.0(0.6-1.6)$ \\
Pregnancy & $161(3.1)$ & $86(53.4)$ & $0.3(0.2-0.4)^{*}$ & $0.3(0.2-0.5)^{*}$ \\
Previous antibiotic prophylaxis & $16(0.3)$ & $15(93.8)$ & $3.7(0.5-27.7)$ & $0.6(0.1-5.7)$ \\
\hline
\end{tabular}

*Significant differences, $p<0.05$

DM diabetes mellitus 
efficient use of diagnostics and correct use of antibiotics might be even more important. Future research is needed to clarify this matter and to study whether improved (point-of-care) diagnostics can improve GPs' management of UTIs. A study at the out-of-hours care in Norway showed promising results by using a diagnostic algorithm instead of a consult with a GP [24]. This could be interesting in the Netherlands as well because our study showed that antibiotic prescription is least in accordance to the guideline in patients visiting the outof-hours GP centre. A further study with more focus on the use of such an algorithm in the Netherlands is therefore suggested.

The number of antibiotic prescriptions is similar to those found by another study in the Netherlands [10]. However, adherence to the guidelines observed in this investigation is far below that observed in another Dutch population [4]. We believe this could be explained by a difference in setting, out-of-hours care, instead of during daytime practice. During out-of-hours care, GPs generally do not have access to patient's previous urine culture results or prior UTI symptoms because of privacy reasons and lack of a shared electronic patient file or treatment relationship during daily practices. Therefore, it is difficult to determine if a patient is part of a risk group or not. Due to lack of this information in medical reports, GPs determine if a patient belongs to a risk group on subjective anamnestic information only. Furthermore, our population could be different from the population analysed by Ganzeboom et al. [4], since they only included three ICPC codes specific for UTI, prostatitis or pyelonephritis. However, these findings are still alarming and future research is therefore needed.

Another remarkable aspect is the fact that two risk factors, male gender and pregnancy, seem to lead to fewer antibiotic prescriptions. This unexpected result was not described in literature before, we do however know that symptoms might be less specific in males [25, 26]. Less specific complaints resulting in a broad differential diagnosis could be a major factor causing the low number of antibiotic prescriptions in these risk groups. However, the same result was found after a subgroup analysis of cases with ICPC codes specific for cystitis, prostatitis and pyelonephritis only (data not shown).

This is the first study to provide an insight into the workload, diagnostic work-up and management of UTIs at GP out-of-hours centres during a full year. The most important strengths of this study were the number of participants (5657 in total) and the fact that the data of these patients were routinely collected during normal GP out-of-hours care. GPs and triage nurses were not aware of the fact that we were studying their management and could therefore not adapt their behaviour to desirable outcomes.

\section{Limitations}

In observational studies, there is a potential for bias from missing data. As discussed earlier, decision making could be difficult for GPs when they do not have full access to a patient's medical report as in daytime practice. This could lead to an underestimation of risk factors that are important to choose the right antibiotic for a patient. However, it is also possible that information is missing in the report at the outof-hours GP centre when a GP has actually asked this but did not write it down properly in the medical report. Furthermore, the written content in medical reports is dependent on the interpretation of the GPs or triage nurses. This could have influenced our results, since we might have categorized some patients in the wrong risk group and compared the choice of antibiotic prescription with the wrong guideline. On the other hand, we believe that the benefits of our design outweigh these limitations.

\section{Conclusions}

An average of eight patients per day contacted their GP out-of-hours centre because of UTI symptoms, of which $74 \%$ received antibiotics. Urinary dipstick was used in almost all patients $(87.5 \%)$ that visited the out-of-hours GP centre with UTI symptoms, but 8 out of 10 patients still received an antibiotic prescription in case of a negative nitrite test. Furthermore, 9 out of 10 patients with an indication did not receive a urine culture, while $44.5 \%$ of all cultures ordered at the out-of-hours GP centre were for patients without an indication for a urinary culture.

Research questions are rising why GPs decide to deviate from UTI guidelines and if GPs are even aware of this fact. Another study showed that a therapy suggestion list in combination with limited availability of ciprofloxacin reduced prescription rates for this antibiotic in cases when other antibiotics are preferred, based on national guidelines [27]. Although UTIs are one of the most common infections, UTI diagnostics and management is still challenging and needs major improvement, especially during out-of-hours GP care.

\section{Abbreviations \\ AB: Antibiotic; DM: Diabetes mellitus; GP: General practitioner; ICPC: International Classification of Primary Care; OR: Odds Ratio; POC: Point- Of-Care; UTI: Urinary tract infection \\ Acknowledgements \\ The authors would like to thank the GP out-of-hours centres in Maastricht and Heerlen for collecting the patient reports.}

\section{Authors' contributions}

All authors contributed in the development of the study protocol and design (MS, JC, GO, PS and EB). MS produced the first draft of the

manuscript. All authors contributed to the interpretation of data and critically revised the manuscript ( $M S, J C, G O, P S$ and EB). EB contributed with the collection of data and statistical analyses. All authors contributed to the final 
version of the manuscript (MS, JC, GO, PS and EB). The author(s) read and approved the final manuscript.

\section{Funding}

No funding was obtained for this study.

\section{Availability of data and materials}

The anonymised data used and analysed during the current study are available from the corresponding author on reasonable request.

\section{Ethics approval and consent to participate}

Ethical approval was obtained from the Maastricht UMC Medical Ethical Committee (2019-1294). The board of directors of the two participating outof-hours centres granted permission to participate in this study.

\section{Consent for publication}

Not applicable.

\section{Competing interests}

The authors declare that they have no competing interests.

\section{Author details}

'Department of Family Medicine, CAPHRI Care and Public Health Research Institute, Maastricht University Medical Centre, P.O. Box 616, Maastricht, MD 6200, The Netherlands. ${ }^{2}$ Department of Medical Microbiology, CAPHRI Care and Public Health Research Institute, Maastricht University Medical Centre, Maastricht, the Netherlands.

Received: 30 June 2020 Accepted: 29 October 2020

Published online: 10 November 2020

\section{References}

1. Hummers-Pradier $E$, Kochen MM. Urinary tract infections in adult general practice patients. Br J Gen Pract. 2002;52(482):752-61.

2. Bent S, Nallamothu BK, Simel DL, Fihn SD, Saint S. Does this woman have an acute uncomplicated urinary tract infection? JAMA. 2002;287(20):2701-10.

3. Schmiemann G, Kniehl E, Gebhardt K, Matejczyk MM, Hummers-Pradier E. The diagnosis of urinary tract infection: a systematic review. Dtsch Arztebl Int. 2010;107(21):361.

4. Ganzeboom KM, Uijen AA, Teunissen DT, Assendelft WJ, Peters HJ, Hautvast JL, Van Jaarsveld $\mathrm{CH}$. Urine cultures and antibiotics for urinary tract infections in Dutch general practice. Prim Health Care Res Dev. 2019;20.

5. Netherlands CS. Statline: the electronic databank of Statistics Netherlands. Retrieved 20 April 2019 from https://statline.cbs.nl/Statweb/publication/ ?DM=SLNL\&amp;PA=83110ned\&amp;D1=0\&amp;D2=0\&amp;D3=0,17-22 \&amp;D4=146\&amp;D5=0\&amp;D6=(l-1)-I\&amp;WW=T.

6. Goossens H, Ferech M, Vander Stichele R, Elseviers M. ESAC project group. Outpatient antibiotic use in Europe and association with resistance: a crossnational database study. Lancet. 2005:365(9459):579-87.

7. Turner D, Little P, Raftery J, Turner S, Smith H, Rumsby K, Mullee M. Cost effectiveness of management strategies for urinary tract infections: results from randomised controlled trial. BMJ. 2010;340:c346.

8. Córdoba G, Holm A, Sørensen TM, Siersma V, Sandholdt H, Makela M, Frimodt-Møller N, Bjerrum L. Use of diagnostic tests and the appropriateness of the treatment decision in patients with suspected urinary tract infection in primary care in Denmark-observational study. BMC Fam Pract. 2018;19(1):65.

9. NethMap-Maran 2019. Retrieved 24 June 2020 from: https://swab.nl/nl/ samenvatting-nethmap-2019.

10. Den Heijer CD, Donker GA, Maes J, Stobberingh EE. Antibiotic susceptibility of unselected uropathogenic Escherichia coli from female Dutch general practice patients: a comparison of two surveys with a 5 year interval. $J$ Antimicrob Chemother. 2010;65(10):2128-33.

11. Bouma M, Geerlings SE, Klinkhamer S, Knottnerus BJ, Platteel TN, Reuland EA, Visser HS. Wolters RJ Herziene NHG-Standaard Urineweginfecties. Huisarts Wet. 2020;63(5):60.

12. Little P, Moore MV, Turner S, Rumsby K, Warner G, Lowes JA, Smith H, Hawke C, Leydon G, Arscott A, Turner D. Effectiveness of five different approaches in management of urinary tract infection: randomised controlled trial. BMJ. 2010;340:C199.
13. Devillé WL, Yzermans JC, Van Duijn NP, Bezemer PD, Van Der Windt DA, Bouter LM. The urine dipstick test useful to rule out infections. A metaanalysis of the accuracy. BMC Urol. 2004;4(1):4.

14. Ditchburn RK, Ditchburn JS. A study of microscopical and chemical tests for the rapid diagnosis of urinary tract infections in general practice. $\mathrm{Br} J \mathrm{Gen}$ Pract. 1990;40(339):406-8.

15. Winkens $R$, Nelissen-Arets $H$, Stobberingh E. Validity of the urine dipslide under daily practice conditions. Fam Pract. 2003;20(4):410-2.

16. Fenwick EA, Briggs $\mathrm{AH}$, Hawke $\mathrm{Cl}$. Management of urinary tract infection in general practice: a cost-effectiveness analysis. Br J Gen Pract. 2000;50(457): $635-9$.

17. Heytens S, De Sutter A, Coorevits L, Cools P, Boelens J, Van Simaey L, Christiaens T, Vaneechoutte M, Claeys $\mathrm{G}$. Women with symptoms of a urinary tract infection but a negative urine culture: PCR-based quantification of Escherichia coli suggests infection in most cases. Clin Microbiol Infect. 2017;23(9):647-52

18. Chae JH, Miller BJ. Beyond urinary tract infections (UTIS) and delirium: a systematic review of UTIs and neuropsychiatric disorders. J Psychiatr Pract. 2015;21(6):402-11

19. van Bergeijk $H$, Berger M. Behandeling van urineweginfecties binnen en buiten praktijkuren. Huisarts wet. 2008:51(9):430-4.

20. Philips H, Huibers L, Holm Hansen E, Bondo Christensen M, Leutgeb R, Klemenc-Ketis Z, Chmiel C, Muñoz MA, Kosiek K, Remmen R. Guidelines adherence to lower urinary tract infection treatment in out-of-hours primary care in European countries. Qual Prim Care. 2014;22(4):221-31.

21. Huisartsenpost OZL. Retrieved 2 March 2020 from http://www. huisartsenpost-ozl.nl/.

22. Huisartsenpost Maastricht \& Heuvelland. Retrieved 2 March 2020 from https://hapmaastricht.nl/nl/organisatie/visie/quick-view\#productiecijfers.

23. Lindbäck H, Lindbäck J, Melhus A. Inadequate adherence to Swedish guidelines for uncomplicated lower urinary tract infections among adults in general practice. Apmis. 2017;125(9):816-21.

24. Bollestad M, Grude N, Lindbaek M. A randomized controlled trial of a diagnostic algorithm for symptoms of uncomplicated cystitis at an out-ofhours service. Scand J Prim Health Care. 2015;33(2):57-64.

25. Wolfs GG, Knottnerus JA, Janknegt RA. Prevalence and detection of micturition problems among 2,734 elderly men. J Urol. 1994;152(5 Part 1): 1467-70.

26. Wolfs GG, Knottnerus JA, Van der Horst FG, Visser AP, Janknegt RA. Determinants of doctor consultation for micturition problems in an elderly male population. Eur Urol. 1998;33(1):1-0.

27. Fagan $M$, Lindbæk $M$, Reiso $H$, Berild D. A simple intervention to reduce inappropriate ciprofloxacin prescribing in the emergency department. Scand J Infect Dis. 2014;46(7):481-5.

\section{Publisher's Note}

Springer Nature remains neutral with regard to jurisdictional claims in published maps and institutional affiliations.

\section{Ready to submit your research? Choose BMC and benefit from:}

- fast, convenient online submission

- thorough peer review by experienced researchers in your field

- rapid publication on acceptance

- support for research data, including large and complex data types

- gold Open Access which fosters wider collaboration and increased citations

- maximum visibility for your research: over $100 \mathrm{M}$ website views per year

At BMC, research is always in progress.

Learn more biomedcentral.com/submission 